\title{
Assessment of Patient Satisfaction with Pharmaceutical Services In A Hospital In Bayelsa State South-South Of Nigeria
}

\author{
*Owonaro A Peter ${ }^{1}$, Eniojukan F Joshua ${ }^{1}$, Owonaro AE Daughter ${ }^{2}$ and Ebinyo C. Nelson ${ }^{2}$ \\ ${ }^{1}$ Public Health Pharmacy Unit, Department of Clinical Pharmacy and Pharmacy Practice, Faculty of Pharmacy, Niger Delta University, Wilberforce \\ Island, Bayelsa State, Nigeria
}

${ }^{2}$ Skypat Pharmacy limited Yenagoa, Nigeria

Submission: April 12, 2017; Published: April 18, 2017

*Corresponding author: Owonaro A. Peter, Public Health Pharmacy Unit, Department of Clinical Pharmacy and Pharmacy Practice, Faculty of Pharmacy, Niger Delta University, Wilberforce Island, Bayelsa State, Nigeria, Email: owonaropeter@gmail.com

\begin{abstract}
Patient satisfaction assessment is regarded as a major pointer of the quality of the pharmacy services patients received in the Hospital. This study was set out to evaluate patient satisfaction with pharmaceutical services.

About 300 respondents agreed to participate after they were made to understand the full details of the study. The questionnaire captured demographic data, drug information provided and how satisfied patients were with the pharmaceutical services provided.About $70 \%$ of respondents reported that information on adverse effects of drugs/side effects was provided. $71 \%$ reported that information on food not to be taken with drugs was provided, $61.3 \%$ reported that information on drug-drug interactions was provided, $62 \%$ reported that information on what to do when adverse effects of drugs/side effects was provided, $67.7 \%$ reported that information on how to store their medications was provided, $76 \%$ reported that information on importance/need for adherence to medication was provided, $71.7 \%$ reported that instruction on the need for follow-up was provided. $45.3 \%$ of respondents rated good satisfaction with information provided to them on adverse effects of drugs/side effects. $39.3 \%$ rated good satisfaction with information provided to them on food not to be taken with drugs, $38.7 \%$ rated good satisfaction with information provided to them on drug-drug interactions, and $35.3 \%$ rated good satisfaction with information provided to them on what to do when adverse effects of drugs/side effects of drugs, $40 \%$ rated good satisfaction with information provided to them on storage of medication. Most of the respondents reported that prescribed drugs were available and affordable. Also on demographical data, Occupation, marital status, monthly income and education recorded statistical correlation. Drug information was provided and patients were satisfied with the information provided. However, pharmacists require continuous education on patient and communication skills.
\end{abstract}

Keywords: Pharmaceutical services; Satisfaction; Hospital and Expectations

\section{Introduction}

Pharmacists are expected to provide advice about medications, screening prescriptions, dispensing and any other management work related to the stocking of medications. Today, most of the Hospitals especially in the developing countries, the rate of patronage by patient is on the increase. The high demand for patients with prescriptions trend continues to grow, to create a necessity for improving workflow management within the outpatient pharmacy settings to provide high-quality services [1-3]. Patient Satisfaction assessment is regarded as a major pointer of the quality of the pharmacy services patients received in the Hospital. This will be pointer whether the services is meeting one's expectations or values. Satisfaction as 'an individual's judgment about the extent to which a product or service provides a pleasurable level of consumption-related fulfillment [4].
In contemporary pharmacy practice there is an increasing trend to rate patient satisfaction level with pharmaceutical services provided. Recent studies have revealed patients' or pharmacists' satisfaction with pharmacy services. Also a closer look at specific disease management and the pharmaceutical services provided in developed countries. This cannot be generalized to other countries, such as developing countries where the pharmaceutical services is still using the traditional method of dispensing medications [5,6]. Pharmaceutical care is key in pharmacy practice globally. This is aimed at providing a better outcome for patients. Patient satisfaction is one of those outcomes. For a pharmacy department to have high patronage, their services must be attractive for patient inflow. Patient satisfaction is likely to affect the image of the Pharmacist and 
pharmacy profession. The need to track patient satisfaction and improvement of pharmaceutical services is vital $[2,7]$.

Drug manufacturing, dispensing and giving pharmaceutical care to patients will continue to be the primary responsibility of a pharmacist. Hence, proper evaluation of the level of satisfaction with medications counseling is a pivotal components for predicting the quality of pharmaceutical services provided by the pharmacy. Medication counseling refers to "providing medication information orally or in written form to the patients or their representatives on directions of use, advice on side effects, precautions, storage, diet, and lifestyle modifications. This will enhance rational use of medicines by the patients and Health professionals. Although, the legal mandate have been given to the Pharmacists to provide medication counseling to every patients, but they have failed to offer drug information to their patients or just provide brief counseling upon patient request $[3,6]$. From the array of studies done so far, this study will further evaluate patient satisfaction with pharmaceutical services in the Hospital out- patient pharmacy department.

\section{Method}

\section{Study population}

This study was carried out in Yenagoa Council Area of Bayelsa State, South- South region of Nigeria with a population 266,008 at the 2006 census [8].

\section{Study Sample}

A total of 500 questionnaires were given, but only 300 respondents agreed to participate after they were made to understand the full details of the study. The sample size was calculated using the formula for evaluating the sample size population [9]. The questionnaire captured demographic data, Pharmaceutical services provided and how they satisfy the pharmaceutical services provided.

\section{Data Analysis}

SPSS version 20 was utilized for data analysis. A t-test was also conducted using one way ANOVA.

\section{Demography}

Table 1: Social Demographic data.

\begin{tabular}{|c|c|c|}
\hline Variable & Freq. & $\%$ \\
\hline & $\mathrm{N}=300$ & \\
\hline \multicolumn{3}{|l|}{ Gender } \\
\hline Male & 137 & 45.7 \\
\hline Female & 163 & 54.3 \\
\hline \multicolumn{3}{|l|}{ Age group } \\
\hline $18-30$ & 111 & 37 \\
\hline $31-50$ & 146 & 48.7 \\
\hline 51 and above & 43 & 14.3 \\
\hline \multicolumn{3}{|l|}{ Occupation } \\
\hline Civil servant & 94 & 31.3 \\
\hline Business & 79 & 26.3 \\
\hline Trader & 33 & 11 \\
\hline Teacher & 21 & 7 \\
\hline Student & 43 & 14.3 \\
\hline Not working & 30 & 10 \\
\hline \multicolumn{3}{|l|}{ Marital status } \\
\hline Single & 96 & 32 \\
\hline Married & 185 & 61.7 \\
\hline Divorced & 13 & 4.3 \\
\hline Widowed & 6 & 2 \\
\hline \multicolumn{3}{|l|}{ Monthly income } \\
\hline $10,000-20,000$ & 128 & 42.7 \\
\hline $21,000-50,000$ & 106 & 35.3 \\
\hline
\end{tabular}




\section{Orthopedics and Rheumatology Open Access Journal}

\begin{tabular}{|c|c|c|}
\hline $51,000-100,000$ & 52 & 17.3 \\
\hline 101,000 and above & 14 & 9.7 \\
\hline Education & 27 & 40.3 \\
\hline Primary & 121 & 48.7 \\
\hline Secondary & 146 & 2 \\
\hline Tertiary & 6 & 52.3 \\
\hline No formal education & & 16.3 \\
\hline Ethnicity & 157 & 5 \\
\hline Ijaw & 49 & 20.3 \\
\hline Igbo & 15 & 20 \\
\hline Hausa & 19 & \\
\hline Yoruba & 60 & \\
\hline Others & & \\
\hline
\end{tabular}

About $54.3 \%$ of the respondents were female, $48.7 \%$ of the respondents were within the age range of $31-50,31.3 \%$ were civil servants, $61.7 \%$ were married, $48.7 \%$ had tertiary education, $42.7 \%$, monthly incomes falls within 10,000-20,000 and $52.3 \%$ were from ijaw (Table 1 ).

\section{Drug information provided at the Pharmacy}

About $70 \%$ of respondents reported that information on adverse effects of drugs/side effects was provided. $71 \%$ reported that information on food not to be taken with drugs was provided, $61.3 \%$ reported that information on drug-drug interactions was provided, $62 \%$ reported that information on what to do when adverse effects of drugs/side effects was provided, $67.7 \%$ reported that information on how to store their medications was provided, $76 \%$ reported that information on importance/need for adherence to medication was provided, $71.7 \%$ reported that instruction on the need for follow-up was provided, $73.7 \%$ reported that information on how medications work was provided, $87.7 \%$ reported that the reasons for taking their medications was provided, $81 \%$ reported that information on name of medications was provided and $62 \%$ reported that information on change of drugs if any side effects or adverse effects occur was provided (Table 2).

Table 2: Drug information provided at the Pharmacy.

\begin{tabular}{|c|c|c|c|c|c|c|}
\hline \multirow[t]{3}{*}{ Information } & \multicolumn{6}{|c|}{ Prevalence } \\
\hline & \multicolumn{2}{|c|}{ Yes } & \multicolumn{2}{|c|}{ No } & \multicolumn{2}{|c|}{ Not sure } \\
\hline & Freq. & $\%$ & Freq. & $\%$ & Freq. & $\%$ \\
\hline Adverse effects of drugs/side effects noticed & 210 & 70 & 76 & 25.3 & 14 & 4.7 \\
\hline Food not to be taken with drugs & 213 & 71 & 79 & 26.3 & 8 & 2.7 \\
\hline Drug-drug interactions & 184 & 61.3 & 98 & 32.7 & 18 & 6 \\
\hline $\begin{array}{l}\text { What to do when adverse effects of drugs/side effects of drugs are } \\
\text { noticed }\end{array}$ & 186 & 62 & 84 & 28 & 30 & 10 \\
\hline Storage of medication & 203 & 67.7 & 80 & 26.7 & 17 & 5.7 \\
\hline Importance/need for adherence to medication regimen & 228 & 76 & 59 & 19.7 & 13 & 4.3 \\
\hline Need for follow-up & 215 & 71.7 & 64 & 21.3 & 21 & 7 \\
\hline How medications work & 221 & 73.7 & 60 & 20 & 18 & 6 \\
\hline Reason for taking medication & 263 & 87.7 & 27 & 9 & 10 & 3.3 \\
\hline Name of medications & 243 & 81 & 43 & 14.3 & 14 & 4.7 \\
\hline Change of drugs if any side effects or adverse effects occur & 186 & 62 & 79 & 26.3 & 35 & 11.7 \\
\hline
\end{tabular}




\section{Orthopedics and Rheumatology Open Access Journal}

\section{Satisfaction with Information Provided at Pharmacy}

About $45.3 \%$ of respondents rated good satisfaction with information provided to them on adverse effects of drugs/ side effects. $39.3 \%$ rated good satisfaction with information provided to them on Food not to be taken with drugs, 38.7\% rated good satisfaction with information provided to them on drug-drug interactions, $35.3 \%$ rated good satisfaction with information provided on what to do when adverse effects of drugs/side effects of drugs, $40 \%$ rated good satisfaction with information provided on storage of medication, $34.3 \%$ rated good satisfaction with information provided on importance/ need for adherence to medication, 32\% rated good satisfaction with information provided on need for follow-up, 36.3\% rated good satisfaction with information provided on how medications works, $32.3 \%$ rated good satisfaction with information provided on name of medication, $34 \%$ rated good satisfaction with information provided on reasons for taking medication, 33\% rated good satisfaction with information provided on evaluation of therapeutic response and 34\% rated good satisfaction with information provided on when to take medications (Table 3).

Table 3: Rating of Respondents' Satisfaction on Information Provided at Pharmacy.

\begin{tabular}{|c|c|c|c|c|c|c|c|c|}
\hline \multirow{3}{*}{ Information } & \multicolumn{8}{|c|}{ Rating } \\
\hline & \multicolumn{2}{|c|}{ Good } & \multicolumn{2}{|c|}{ V. Good } & \multicolumn{2}{|c|}{ Excellent } & \multicolumn{2}{|c|}{ Not sure } \\
\hline & Freq & $\%$ & Freq & $\%$ & Freq & $\%$ & Freq & $\%$ \\
\hline adverse effects of drugs/side effects noticed & 136 & 45.3 & 69 & 23 & 39 & 13 & 56 & 18.7 \\
\hline Food not to be taken with drugs & 118 & 39.3 & 71 & 23.7 & 57 & 19 & 54 & 18 \\
\hline Drug-drug interactions & 116 & 38.7 & 64 & 21.3 & 58 & 19.3 & 62 & 20.7 \\
\hline $\begin{array}{l}\text { What to do when adverse effects of drugs/side } \\
\text { effects of drugs are noticed }\end{array}$ & 106 & 35.3 & 66 & 22 & 32 & 10.7 & 96 & 32 \\
\hline Storage of medication & 120 & 40 & 72 & 24 & 51 & 17 & 57 & 19 \\
\hline $\begin{array}{l}\text { Importance/need for adherence to medication } \\
\text { regimen }\end{array}$ & 103 & 34.3 & 92 & 30.7 & 61 & 20.3 & 44 & 14.7 \\
\hline Need for follow-up & 96 & 32 & 86 & 28.7 & 52 & 17.3 & 66 & 22 \\
\hline How medications work & 109 & 36.3 & 87 & 29 & 62 & 20.7 & 42 & 14 \\
\hline Name of medication & 97 & 32.3 & 88 & 29.3 & 74 & 24.7 & 41 & 13.7 \\
\hline Reason for taking medication & 102 & 34 & 88 & 29.3 & 79 & 26.3 & 31 & 10.3 \\
\hline Evaluation of therapeutic response & 99 & 33 & 62 & 20.7 & 41 & 13.7 & 98 & 32.7 \\
\hline When to take medications & 103 & 34.3 & 99 & 33 & 75 & 25 & 23 & 7.7 \\
\hline
\end{tabular}

\section{Affordability and Availability}

Regarding affordability of prescribed drugs 89\% reported that it was affordable. $90 \%$ of the respondents reported that prescribed drugs were available, $78 \%$ reported that the drugs were expensive (Table 4),

Table 4: Affordability and Availability.

\begin{tabular}{|c|c|c|c|c|c|c|}
\hline \multirow[t]{2}{*}{ Variable } & \multicolumn{2}{|c|}{ Yes } & \multicolumn{2}{|c|}{ No } & \multicolumn{2}{|c|}{ Not sure } \\
\hline & Freq. & $\%$ & Freq. & $\%$ & Freq. & $\%$ \\
\hline Were you able to afford drugs prescribed to you? & 269 & 89.7 & 19 & 6.3 & 12 & 4 \\
\hline \multirow[t]{3}{*}{ Were drugs prescribed to you available } & 270 & 90 & 16 & 5.3 & 14 & 4.7 \\
\hline & \multicolumn{2}{|c|}{ Affordable } & \multicolumn{2}{|c|}{ High } & \multicolumn{2}{|c|}{ Low } \\
\hline & Freq. & $\%$ & Freq. & $\%$ & Freq. & $\%$ \\
\hline How expensive are your drugs? & 236 & 78.7 & 49 & 16.3 & 15 & 5 \\
\hline
\end{tabular}

\section{Socio-Demographic Variables on Satisfaction}

Regarding socio demographic variables with satisfaction gender, Age recorded no correlation, whereas, Occupation,

marital status, monthly income and education recorded statistical correlation (Table 5). 
Table 5: Impact of Socio-Demographic Variables on Satisfaction.

\begin{tabular}{|c|c|c|c|}
\hline Predictor & $\begin{array}{c}\text { Standardized } \\
\text { coefficient }\end{array}$ & CI at 95\% & p-value \\
\hline Beta & & \\
\hline Age & 0.022 & -0.266 & 0.711 \\
\hline Occupation & 0.097 & -0.228 & 0.8 \\
\hline Marital status & 0.064 & -0.085 & 0.135 \\
\hline $\begin{array}{c}\text { Monthly } \\
\text { income }\end{array}$ & 0.05 & -0.174 & 0.34 \\
\hline Education & -0.159 & -0.27 & $0.008^{*}$ \\
\hline
\end{tabular}

${ }^{*} \mathrm{p}$-value is $<0.05$ significant; $\mathrm{Cl}$ : Confidence Interval

\section{Discussion}

The study revealed that more female participated within the age group of 31-30 years. This is not surprising since female visit to the Hospital is more common and frequent [10]. Majority of the respondents were civil servants, married and holders of tertiary education qualifications. Their monthly incomes falls within 10,000-20,000 and are I Jaw speaking people. This is expected since Bayelsa State is and I jaw speaking people. Hence, more I jaw speaking people are expected to participate in this study.

\section{Drug information provided at the Pharmacy}

Regarding drug information provided at the pharmacy most of the respondents reported that information on adverse effects of drugs/side effects was provided, food not to be taken with drugs, drug-drug interactions, what to do when adverse effects of drugs/side effects, how to store their medications, Importance/ need for adherence to medication, need for follow-up, how medications works, reasons for taking their medications, name of medications and change of drugs if any side effects or adverse effects was provided. Pharmacist role in providing advice about medications, screening prescriptions, dispensing and any other management work related to the stocking of medications remain sacrosanct. In contemporary practice pharmaceutical care is now the corner stone of pharmacy practice globally. This will help to improve patient's better on adherence, clinical and economic outcomes. Studies have shown that Pharmacist held unto the ethics of their profession by providing services as mandated legally. Drug information is given verbally and in written form to patients. This has drastically reduced irrational use of drug. Also patients have equally reported the drug information rendered to them was beneficial to them. However, other studies have reported lack of information on the need on follow-up and documentation in most department of Pharmacy in the Hospital. [11-14].

Regarding satisfaction with Information provided at pharmacy, most of the respondents reported that they were satisfied with adverse effects of drugs/side effects, Food not to be taken with drugs, drug-drug interactions, on what to do when adverse effects of drugs/side effects of drugs, storage of medication, importance/need for adherence, how medications works, name of medication, reasons for taking medication, evaluation of therapeutic response and when to take medications. Several studies have reported that patient satisfaction with pharmaceutical services was provided. Also patient was willing to receive pharmaceutical information. Their satisfaction is likely associated with the provision of service promptness, pharmacist attitude/ communication skills, medication counseling, pharmacy location, and waiting area $[3,5,15-17]$. A study in Nigeria reported that patient received low satisfaction with pharmaceutical services. This low satisfaction with pharmaceutical services provide may be connected to too high expectation from the patients mostly the literates $[7,18,19]$.

Patient satisfaction with pharmaceutical services is subjective. It is 'an individual's judgment about the extent to which a product or service provides a pleasurable level of consumption-related fulfillment. This level of satisfaction is based on patient expectations. Hence satisfaction varies based on the patient level of education and exposure. Satisfying the literate require more skills by being at the top of your profession. In the same line satisfaction of the patient that are blind, deft and dump will require a greater skills. For the illiterate it will require special skills like the blind, deft and dump. Hence the need of perfect communications skills with adequate knowledge of drugs and disease state is a panacea of providing excellent drug information to the understanding and clarity of the patient which will translate to satisfaction of pharmaceutical services provided. Most pharmacists have deficiencies in communication skills which have impaired adequate provision of pharmaceutical services [1]. Drug information closer to patient via the use of internet. Every educated patient with a reading culture has some form of knowledge/information about his/her medication or disease state before visiting the Hospital or Health professional. To satisfy the generality of patient that visit pharmacy department in any Health facility, the Pharmacists is expected to have a firsthand knowledge of drugs and the disease state of the patient to inform/educate the patient more than what he/ he already knows. To enhance this, Pharmacist is encouraged to engage in mandatory continuous education to be at the very best of their practice as an expert of drug [3].

\section{Affordability and Availability}

Regarding affordability most of prescribed drugs were affordable and available. Accessibility refers to physical access to the products, or where the products can be delivered to patients. It involves the overall organization of the health system and especially, its procurement, supply and dispensing systems. In order to embrace the notion of access to treatment, accessibility in this publication is also understood as encompassing factors such as access to prescribers and proper education 
and information about the products. Affordability refers to a product's cost vs. the ability and willingness of people (as well as health systems and third-party payers) to pay for it. Affordability entails a product's price components (manufacturing, supply, taxes, mark-ups), as well as policies and other factors that affect these components - such as pricing and reimbursement policies, intellectual property and competition laws, regulatory standards and requirements. Availability is defined as the presence in a country of products that meet the population's health needs. It refers to the range of products marketed in a country; which of them are selected by the health system; and how and according to which indications and guidelines they should be prescribed and delivered. The availability and affordability of prescribed drugs might have influence patients reported level of satisfaction with pharmaceutical services [20-22].

On socio demographic variables with satisfaction with pharmaceutical services; gender, Age recorded no correlation whereas, Occupation, marital status, monthly income and education recorded statistical correlation with pharmaceutical service satisfaction.

\section{Conclusion}

The study revealed that more female participated within the age group of 31-30 years. Pharmaceutical services were provided and Patient reported that they beneficiated from the drug information provided. Also they were equally satisfy with the drug information provided to them. Also medications were affordable and available to patients. Demographical data shows Occupation, marital status, monthly income and education recorded statistical correlation.

\section{References}

1. Ala'Eddin MA, Mohammad AS, Saleh AS, Omar ZA, Hussein MA (2016) Factors Influencing Patient Satisfaction with Pharmacy Services: An Empirical Investigation at King Fahd Armed Forces Hospital, Saudi Arabia. International Journal of Business and Management 11(9).

2. Al-Arifi MN (2012) Patients' perception, views and satisfaction with pharmacists' role as health care provider in community pharmacy setting at Riyadh, Saudi Arabia. Saudi Pharm J 20(4): 323-330.

3. Wilcock M, Harding G (2011) Patients' experience of hospital pharmaceutical services.nInt J Pharm Pract 19(6): 400-407.

4. Karen JM (2005) Continuing Education brought to pharmacists by Pfizer inc., USPG.

5. Khalaf A, Mohamed AH, Ibrahim A (2014) Patient Satisfaction with the Health Services Provided by the Pharmacist at a General Hospital in Riyadh, Saudi Arabia. European Journal for Person Centered Healthcare 2(4).

6. Seungwon Y, Dasohm K, Hye JC, Min Jung C (2016) A comparison of patients' and pharmacists' satisfaction with medication counseling provided by community pharmacies: a cross-sectional survey. BMC Health Ser Res 16: 131.

7. AzukaC Oparah, Ehijie FO, Enatoand Obehi A, Akoria (2004) Assessment of Patient Satisfaction with Pharmaceutical Services in a Nigeria Teaching Hospital. IJPP 12: 7-12.

8. National Population Commission, Nigeria 2006 census Nigeria 2006 census.

9. Araoye MO (2003) Research methodology with statistics for health and social sciences. Nathadex Publishers Ilorin, pp. 117-118.

10. Catherine LK, Thomas R, Scott D, Rashmi UK, Carrie K, et al. (2015) Emergency Department Visits and Injury Hospitalizations fornFemale and Male Victims and Perpetrators of Intimate Partner Violence. Advances in Emergency Medicine 2015: 11.

11. Blom AT, Rens JA (1989) Information about over-the-counter medication: the role of the pharmacy. Patient Educ Couns 14(3): 181189.

12. Himanshu P, Ramesh A, Ramya S, Parthasarathi G (2015) Drugs and Therapeutic Information Service Provided by Clinical Pharmacists for an Improved Patient Care: an Experience from a Tertiary care Teaching Hospital. 8(6): 0974-2441.

13. Stephen B (2009) Pharmacy Distribution of Consumer Drug Information Emerges as a Problem. P Tn34(2): 65.

14. Sushanta KD, Souvick A, Anand V, Saurabh G (2014) Drug Information Service as Pharmaceutical Care; Provided by Clinical Pharmacists' in a South Indian Government Hospital. Austin J Pharmacol Ther 2(6): 1033.

15. Imran FK (1988) Measuring patients' satisfaction with pharmaceutical services at a public hospital in Qatar. International Journal of Health Care Quality Assurance ISSN: 0952-6862.

16. Okoye MO, Ukwe VC, Okoye TC, Adibe MO, Ekwunife OI (2014) Satisfaction of HIV patients with pharmaceutical services in South Eastern Nigerian hospitals. Int J Clin Pharm 36(5): 914-921.

17. Abebe TB, Erku DA, Gebresillassie BM, Haile KT, Mekuria AB (2016) Expectation and satisfaction of HIV/AIDS patients toward the pharmaceutical care provided at Gondar University Referral Hospital, Northwestern Ethiopia: a cross-sectional study. Patient Prefer Adherence 10: 2073-2082.

18. Abdrrahman SS, Fitsum ST, Genet G, Elsabet M, Meseret T, et al. (2015) Satisfaction of clients with the services of an outpatient pharmacy at a university hospital in northwestern Ethiopia: a cross-sectional study. BMC Health Serv Res 15: 229.

19. Adil Abd EM (2016) Patients' perspectives on the quality of pharmaceutical services in Saudi hospitals. Int J Res Pharm Sci 6(3): 36-40.

20. Harinder SC, Nazaire St. F, Lisa B (2013) Availability, prices and affordability of essential medicines in Haiti. J Glob Health 3(2): 020405.

21. Jaime E, Joan R, Antonio O (2011) WHO/HAI Project on Medicine Prices and Availability.

22. Jon Schommer (2011) A Professor of the University of Minnesota College. 
This work is licensed under Creative Commons Attribution 4.0 License DOI: $10.19080 /$ OROAJ.2017.06.555686
Your next submission with Juniper Publishers will reach you the below assets

- Quality Editorial service

- Swift Peer Review

- Reprints availability

- E-prints Service

- Manuscript Podcast for convenient understanding

- Global attainment for your research

- Manuscript accessibility in different formats ( Pdf, E-pub, Full Text, Audio)

- Unceasing customer service

Track the below URL for one-step submission https://juniperpublishers.com/online-submission.php 